\title{
What Makes a City Accessible and Inclusive?
}

\begin{abstract}
The urban-focused Capability Model of Disability (CMD) presented here outlines three key features for city and urban planning processes: rethinking the relationship between people with disabilities and their environment, a development-based framework for inclusive policymaking along nine policy dimensions, and the concept of salience to measure cultural coherence and likelihood for a society to adopt international human rights norms at the local level. The CMD framework is applied to a set of nine basic primary goods necessary for inclusive urban planning and policymaking, which are divided into basic functionings (health, rehabilitation, education, and employment) and basic freedoms (mobility, accessibility, being included in the community, political and public participation, and awareness raising). This chapter provides insights into what this integrated model looks like and how it addresses endemic challenges that impede full implementation of comprehensive rights, policies, and norms across sectors and scales.
\end{abstract}

Keywords Basic functionings $\bullet$ Basic freedoms $\bullet$ Implementation

- Human rights $\bullet$ Inclusion $\bullet$ Equity $\bullet$ Access $\bullet$ Capability Approach

- Primary goods $\bullet$ Human development $\bullet$ Community development

- Inclusion policymaking • Evaluative frameworks 
I have dedicated my life to exploring the dominant debates in policy, planning, and development, with a focus on inclusive urban development. In this chapter, I address these issues and argue that the Capability Model of Disability (CMD) effectively addresses the current gaps in theories of justice, development and urban planning. As discussed in Chap. 2, the rights-based model emphasizes the role that social barriers and attitudes can play to marginalize groups such as persons with disabilities and older persons. However, the rights-based model does not address how policymakers can assess and measure the motivations behind social actions and perceptions. I propose that successful rights-based policy interventions assess the salience of international norms on the local level. Doing so I argue offers a tangible and novel approach to achieve better results. Herein, I explain how the concept of salience fits into a new, more responsive, and culturally relative development-based framework. This chapter offers insight into what this integrated rights-based model could look like and how it effectively addresses the endemic challenges that impede full implementation of comprehensive laws, policies, and norms across sectors and scales.

\section{Salience in an Inclusive and Culturally Sensitive Development Framework}

Salience can be used as a tool in planning, policymaking, and development. As a scholar I have been especially interested in how the concept of salience operationalizes a measure for cultural understanding-the proclivity for a society to adopt social change, but also the potential challenges or failures for not incorporating salience. As a practitioner I have explored metrics to measure salience and have argued in favor of their importance. It is, however, a tricky concept to operationalize. Both Sen and Nagata pointed to the importance of social attitudes but failed to incorporate an effective measure. How can we measure social attitudes toward persons with disabilities across cultures and how can we link such attitudes to greater concepts of development? Can salience lead to a new and more integral, comprehensive, and inclusive development framework for persons with disabilities? 


\section{The Central Role of Salience in Implementation of International Norms}

Salience plays an important role in the implementation of international norms. Andrew Cortell and James Davis Jr. (2000) point to shortcomings in the methodology of assessing the domestic impact of international law. Their research on salience offers ways to assess sovereign (state) behavior in light of international agreements or treaties such as the United Nations Convention on the Rights of Persons with Disabilities (CRPD). Cortell and Davis propose that behavior can be analyzed in terms of two nationallevel factors: the structural context within which the domestic policy debate transpires, and the domestic salience or legitimacy of the norm.

\section{Domestic Salience or Legitimacy of the Norm}

For Cortell and Davis (2000), international norms are prescriptions for action in situations of choice within the domestic political context, and salience refers to the varying strength of the international norm on the local level ( $i d$. at 68,69$)$. Salience requires that there is a degree of attitudinal support at a local level that can help drive the norm's legitimacy in the national arena so that the norm can be "accepted as a guide to conduct and a basis for criticism, including self-criticism" ( $i d$. at 69).

Cortell and Davis (2000) argue that domestic salience is not necessarily helpful in understanding a particular instance of norm compliance. Its utility comes in understanding the factors that promote an international norm attaining an "ought" status in the domestic political arena. The authors found that international norms become salient domestically when looking at five key factors: cultural match, national political rhetoric, the material interests of domestic public actors, domestic political institutions, and preexisting socializing forces. They cite Henkin, an eminent international lawyer, author of How Nations Behave: Law and Foreign Policy (1979). In it, Henkin argues that before a nation observes a law, its people must fully accept its obligations and, by extension, accept the values that underpin the law. He argues that "when international law or some particular norm or obligation is accepted, national law will reflect it, the institutions and personnel of government will take account of it, and the life of the people will absorb it" (Henkin 1979, 60). Henkin notes that compliance or violation of a law ultimately rests on deeply held social attitudes and beliefs. We will explore the function of attitudes and beliefs in later sections. 


\section{Disability vis-à-vis Domestic Salience}

Examining domestic salience within the context of disability rights norms provides a useful indicator for predicting the impact of an international norm in domestic policy debates. Diverse approaches to disability should be seriously considered when developing policy. Identifying a cultural match on disability rights would thus indicate that domestic actors are likely to treat disability rights as a given and would instinctively recognize the obligations associated with disability rights laws and policies. This, however, is often not the case.

Hays argues that culture defines and is defined by the social processes that are learned and perpetuated through society. Karr (2009) builds upon Hays" definition that culture is "all of the learned behaviors, beliefs, norms, and values that are held by a group of people and passed on from older members to newer members, at least in part to preserve the group" (Hays 1996, 333). Like Hays, Karr $(2009,2)$ argues that "disability can be seen as a trans-cultural (or etic) occurrence in that it is an issue that applies to all cultures. It can also be seen as a culture-specific (or emic) issue, which emphasizes the need for intimate awareness and knowledge of the culture." It is useful to note that in describing how domestic salience can be understood, Cortell and Davis use the term cultural match. Herein, salience is cultural and therefore can be used to describe the preexisting social, legal, or cultural factors that shape the discourse of international norms in domestic policy debates. Salience strengthens the actual impact that awareness raising and public education programs can have in sensitizing the general public toward the issues, needs, and rights of persons with disabilities.

\section{Cultural Match: Case of "Independent or Community Living"}

"Individualism" refers to societies with loose individual ties-everyone is expected to look after themselves, while "collectivism" refers to societies whose members are integrated into strong cohesive groups, which provide protection in exchange for loyalty (Hofstede 1991, 51). Individualistic cultures are found primarily in Europe, North America, and Australia, and demonstrate strong characteristics of autonomy. Collectivistic cultures are found mostly in Asia, South America, the Middle East, and Africa, and are characterized by interdependence and a collective identity (Karr 2009).

Cheloff (2000) studied the influence of religious and cultural values and characteristics on perceptions of and attitudes toward children with 
disabilities. An individualistic culture showed a greater willingness toward inclusive views regarding community integration and education. In contrast, the collectivistic culture took a more cautious and protective view, limiting the interaction between children with and without disabilities. The individualistic culture also demonstrated more positive views regarding future outcomes for children with disabilities, such as the ability to hold meaningful employment, marry, and have a family (id.). Cheloff's and Karr's studies demonstrate the varying perceptions of disability across cultures-many having negative attitudes toward persons with disabilities (intensified by culturally embedded views).

The idea of "self-determination" is similarly subject to cultural interpretation. Turnbull and Turnbull $(2001,56)$ argue that self-determination is culturally laden and determined by cultural values. Documented definitions of self-determination are mostly rooted in a Western, modern, or Anglo-European orientation and recognize the importance of honoring and respecting one's cultural values (Hanson et al. 1998). Determination and self-determination are foundational to human dignity and human agency. The following chart contrasts some of these modern/Western cultural values and practices with those of traditional cultures in terms of societal approach toward disability (Table 3.1).

Table 3.1 Contrasting beliefs, values, and practices developed by the US Department of Agriculture and the US Department of Health and Human Services (as cited in Hanson et al. 1998)

\begin{tabular}{ll}
\hline Modern/Western approaches & Traditional approaches \\
\hline Personal control over the environment & Fate \\
Change & Maintain \\
Time dominates & Human interaction dominates \\
Human equality & Hierarchy/rank/status \\
Individualism/privacy & Group welfare \\
Self-help & Birthright inheritance \\
Competition & Cooperation \\
Future orientation & Past orientation \\
Action/goal/work orientation & "Being" orientation \\
Informality & Formality \\
Directness/openness/honesty & Indirectness/ritual/“face" \\
Practicality/efficiency & Idealism/theory \\
Materialism & Spiritualism/detachment \\
\hline
\end{tabular}


Self-determination is also central to ensuring that the values of justice and access are realized for undervalued, or overlooked, segments of society, such as persons with disabilities and older persons. As such, defining and implementing self-determination through, for example, independent living programs could prove problematic in cultures where one's family establishes one's social role. In those cases, the social role has a social value, and independence or autonomy may actually deprive the individual of their social role and lower their social standing and even quality of life. Therefore, it is important that we understand and respect cultural differences in independent and community living and understand the multitude of ways in which one can execute self-determination (Karr 2009). Turnbull and Turnbull (2001) advocate for more research to conceptualize self-determination representing a broad range of cultural diversity.

\section{Salience and the Will for Comprehensive Social Sector Reforms}

Theories, ideas, beliefs, and cultural perspectives have significant implications for planners and policymakers. Cultural perspectives in particular directly challenge dominant paradigms in the theory and practice of urban and regional planning as well as in social policy development. States struggle to balance opposing pressures of economic growth and social equity. They also often lack the capacity or political or social will necessary to execute comprehensive social sector reforms. Such reforms are further strengthened through an active civil society that understands and mobilizes for them.

Salience serves two important purposes in this regard; it can serve as a catalyst or as a retardant to furthering social sector reforms. Positive salience serves as a catalyst in deliberations on disability policy and can further empower and increase the meaningful participation of persons with disabilities in the implementation and practice of disability rights norms at the local level.

\section{The Need for an Integrated Model of Disability}

From 2002 to 2006, I worked with the world's leading human rights experts on drafting the CRPD. Since then I have directed research with advocates, scholars, and practitioners in nearly two dozen countries to formulate innovative and more holistic approaches to disability rights in policy 
and practice. ${ }^{1}$ According to Tom Shakespeare (2008), a disability studies scholar from the UK, disability is a complex, scalar, multi-dimensional phenomenon and any analysis on the topic must take into account the social understanding and construction of disability. The predominant constructions of disability have perpetuated unnecessary and unjust social exclusions, which continue to be widespread and persistent. An applicable or remedial theory of disability should be able to measure the social values, beliefs, and attitudes that devalue and obstruct social inclusion. Most practitioners in the field of disability rights agree that a more integrated and applicable rights-based approach grounded on the principles of the CRPD should be developed. Such an approach should ideally integrate multiple dimensions (or spheres of life) into the policy formulation and implementation process.

Sophie Mitra (2006) addresses this from the viewpoint that disability can be understood as being the result of a variety of factors that includes the individual's personal characteristics such as age, race, or gender as well as their environment and the resources available to them in order to function within that environment (Fig. 3.1).

The ultimate goal of an integrated model would be to better achieve social inclusion. Such a model would highlight specific dimensions that can more effectively address the endemic challenges that impede full implementation of comprehensive disability rights, policies, and norms across sectors and scales. It would additionally incorporate attitudes and beliefs as benchmark and target development interventions across multiple dimensions. The result should be a strengthening of the capacities of both institutions and citizens through participatory mechanisms.

\section{An Integrated Capability Model of Disability}

Since Mitra's and Robyn's seminal work on the Capability Model of Disability, other authors have discussed the ways that Sen's Capability Approach (CA) can strengthen the social model of disability. My own contribution to the Capability Model of Disability incorporates both my

\footnotetext{
${ }^{1}$ Many practitioners in the field talk about the fact that the systems are fragmented, weak, or underfunded. Some blame the diverse cultural approaches and understandings of disability or the administrative challenges involved with such reforms. Others cite negative social attitudes or the lack of capacity or funding necessary to implement even the most basic rights.
} 


\section{Policy Coherence for Rights Model}

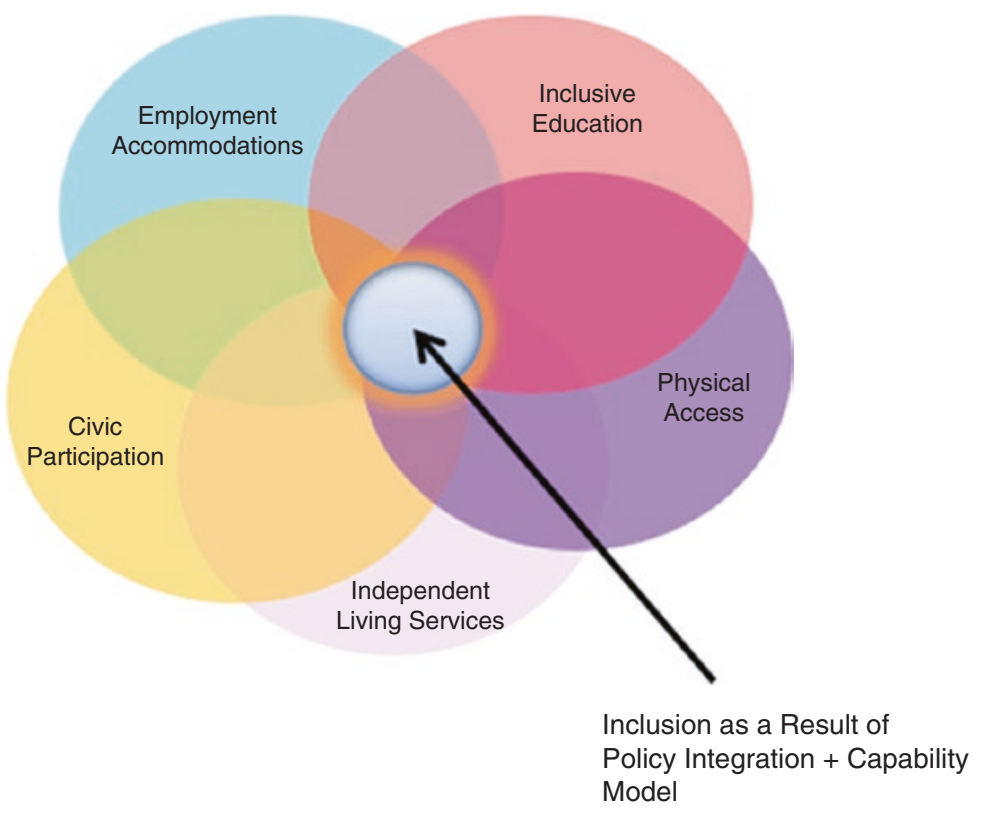

Fig. 3.1 A holistic and integrated approach to disability policy requires a coordinated and concerted effort by various agencies and institutions. Identifying and resolving inequality and gaps in outcomes is key to improving the lived experience of persons with disabilities. (Modified figure. Source: Navtej Dhillon and Tarik Yousef. Inclusion: Meeting the 100 Million Youth Challenge, p. 24)

personal and professional experiences. It builds upon all the previous work and addresses a few important theoretical gaps. In this book, when I refer to the Capability Model of Disability, I am specifically discussing the new key elements and a new framework that I feel better integrates concepts of justice, planning, and development. The point of departure for my model lies in the identification of social inclusion through a robust institutional approach to access and governance as the main drivers of inclusive development.

There are three fundamental features that I argue should be added to the discourse on the Capability Model of Disability. These features form a new and more integrated Capability Model of Disability. Such a model 
1. Characterizes disability as a failure between an individual and their physical, social, or institutional environment along some dimension rather than as a deviation from the norm of human functioning. This model exemplifies the dominant debates in disability studies and can be thought of as an extension to the social model of disability. It fundamentally shows that the concept of a "disabled" person is a social construct and asserts that there is only a capability-deprived person with respect to some physical or social environment.

2. Defines the concept of salience and uses it to assess cultural understanding and the readiness of a society to adopt international norms across sectors and scales. By doing so, it addresses particular social, cultural, and attitudinal barriers to social inclusion.

3. Offers a set of basic primary goods that are assessed through five assessment criteria for policy or primary goods effectiveness. This assessment framework is applied to a set of basic primary goods necessary for inclusive planning and policymaking. The basic primary goods are divided into:

a. Basic functionings (health, rehabilitation, education, and employment)

b. Basic freedoms (mobility, accessibility, being included in the community, political and public participation, and awareness raising)

These concepts are then brought into discussion within a holistic framework to assess equity. The framework includes the following five pillars:

1. Laws: Includes national and international rights and norms

2. Leadership: Includes executive and budgetary support

3. Institutional Capacity: Includes administrative and coordinating abilities of implementing agencies

4. Attitudes: Beliefs and behaviors of the general population toward targeted groups

5. Participation: Includes substantive engagement and representation by targeted beneficiaries and relevant stakeholders

\section{Evaluating the Utility of the Capability Model of Disability}

Mitra (2018) elaborates on the Capability Approach as a framework for evaluation of disability and civil rights. She underscores the importance of the evaluative dimensions of disability and notes Sen's reluctance to 
propose a list of capabilities and functionings to assess poverty (and disability-related issues). Mitra stresses the fact that people with impairments and disability ought to be involved in selection of criterion of assessment in a participatory fashion and raises the question as to whether policy should focus on addressing issues in capabilities or functionings. However, Mitra also makes the crucially important observation that needs and points of focus are value-based and vary based on those who are able to define these needs and focuses. These questions and concerns are addressed by the CMD approach.

Trani et al. (2011) help strengthen my analysis by delving into how the CA informs gaps in disability-related research, especially in data collection, policy implementation, and assessment. The authors propose a new measure of both functionings and capabilities by analyzing the gap between the two measures. Trani et al. consider the CA's insight on conversion factors: the ability to internally and externally convert endowments, income, and other social resources into tangible functionings and personal aspirations. Notably, the authors hint at the improvement of measurement of disability and its relevance for policy, but whose stakeholders' agency (i.e., people with disabilities) has yet to be acknowledged by those in power. This phenomenon is called negation, in which people with disabilities have little to no choice with respect to outcomes that they choose in social life. Thus, these sources provide excellent insight into how to develop better policies for people with disabilities with a more integrated CMD framework.

\section{Defining Desivable Outcomes}

The CMD, when applied to policy, can help define, measure, and guide successful outcomes. My model builds off the important work done by many others, most notably by building on the important work of Sophie Mitra (2006). Herein the model addresses how the capacities of both persons with disabilities and the institutions that work with them can build the necessary capabilities to more effectively implement and promote policy coherence. It supports three key outcomes that could help alter the individual's social positioning:

1. Equality of Opportunity: Persons with disabilities are considered to be part of society and are considered equal stakeholders in development. They are afforded full and substantive citizenship on an equal basis with others. Capability deprivation, through the implicit 
and/or tacit denial of reasonable accommodations, is seen as an unjust form of discrimination that could be prosecuted by law.

2. Increase Social Role Valorization: Social attitudes toward persons with disabilities are positive, showing no areas of distinction compared to non-disabled individuals. Public information and strategic efforts exist to raise awareness of what persons with disabilities can do in the event that their capability deprivations are omitted. Persons with disabilities encounter no social barriers and enjoy increased understanding from families, communities, and the general public. Their functional difference is mediated by reasonable accommodations and an ethos of social inclusion, habilitation, solidarity, and justice.

3. Increase Basic Functionings and Freedoms: A set of basic primary goods are identified, thereby paving the way for more targeted approaches toward social inclusion. Basic functionings increase through a closer and more integrated approach to health, rehabilitation, education, and employment. Basic freedoms increase through a closer and more integrated approach to mobility, accessibility, community inclusion, political and public participation, and awareness raising. A robust participatory and community development component is incorporated into the model, with an underlying premise that active participation and engagement by target groups strengthens all other areas that affect them. This participatory element will allow for an increased level of cooperation, accountability, and transparency. This topic will be revisited later in the chapter.

The CMD defines social inclusion in the spirit of the CRPD and identifies capability enhancement and the elimination of capability deprivation as the outcome of all successful disability policies. As was stated above, the provision of rights is strongly linked to the elimination of capability deprivation. The CMD applies social justice debates and adds a disability dimension by defining desirable outcomes for persons with disabilities. The CMD establishes empirical linkages that incorporate representation, equality of opportunity, and increased social role valorization. It thus offers practitioners a theoretically and empirically grounded framework for policy development and implementation (Table 3.2).

The CMD, as developed and applied here, can help frame the urban dimensions that link individual functions with social and environmental freedoms. The goal of this research is to strengthen the capacities of 
Table 3.2 Comparison of Sen's, Nagata's, and Pineda's approaches to the key evaluative aspects

\begin{tabular}{|c|c|c|c|}
\hline Evaluative aspect & Sen & Nagata & Pineda \\
\hline $\begin{array}{l}\text { Well-being } \\
\text { concept }\end{array}$ & $\begin{array}{l}\text { Functionings and } \\
\text { capabilities }\end{array}$ & $\begin{array}{l}\text { Human rights and } \\
\text { inclusive development }\end{array}$ & $\begin{array}{l}\text { Capabilities and social } \\
\text { inclusion }\end{array}$ \\
\hline $\begin{array}{l}\text { Leading criterion } \\
\text { for evaluating } \\
\text { development } \\
\text { progress }\end{array}$ & $\begin{array}{l}\text { Human capabilities, } \\
\text { equality of } \\
\text { outcomes, fairness } \\
\text { and justice in } \\
\text { institutional } \\
\text { arrangements }\end{array}$ & $\begin{array}{l}\text { Social awareness, social } \\
\text { inclusion, human rights }\end{array}$ & $\begin{array}{l}\text { Functionings, } \\
\text { freedoms, } \\
\text { participation, salience }\end{array}$ \\
\hline $\begin{array}{l}\text { Measurement } \\
\text { tools favored }\end{array}$ & $\begin{array}{l}\text { Human outcomes, } \\
\text { deprivational and } \\
\text { distributional } \\
\text { measures }\end{array}$ & $\begin{array}{l}\text { Scaled attitudes toward } \\
\text { persons with } \\
\text { disabilities, focus } \\
\text { groups }\end{array}$ & $\begin{array}{l}\text { Interviews, surveys, } \\
\text { focus groups, } \\
\text { document analysis, } \\
\text { and salience to } \\
\text { measure capability } \\
\text { deprivations }\end{array}$ \\
\hline Agency aspect & $\begin{array}{l}\text { People have agency; } \\
\text { they are ends and } \\
\text { means to } \\
\text { development }\end{array}$ & $\begin{array}{l}\text { People have weak } \\
\text { agency; they are a } \\
\text { means to development. } \\
\text { Human resource for } \\
\text { economic activity. } \\
\text { Growth is the ends }\end{array}$ & $\begin{array}{l}\text { People have agency; } \\
\text { they are the ends and } \\
\text { means toward social } \\
\text { inclusion }\end{array}$ \\
\hline $\begin{array}{l}\text { Mobilizing } \\
\text { agency }\end{array}$ & $\begin{array}{l}\text { Individual action } \\
\text { and collective action }\end{array}$ & Collective action & $\begin{array}{l}\text { Coordinated } \\
\text { individual, community, } \\
\text { and state actions }\end{array}$ \\
\hline $\begin{array}{l}\text { Key operating } \\
\text { goals }\end{array}$ & $\begin{array}{l}\text { Expanding people's } \\
\text { choices (social, } \\
\text { economic, political) }\end{array}$ & $\begin{array}{l}\text { Improving social } \\
\text { attitudes and realizing } \\
\text { human rights }\end{array}$ & $\begin{array}{l}\text { Enhancing basic } \\
\text { functionings and } \\
\text { freedoms by increasing } \\
\text { participation }\end{array}$ \\
\hline $\begin{array}{l}\text { Policy concern } \\
\text { with distribution } \\
\text { of benefits and } \\
\text { costs }\end{array}$ & $\begin{array}{l}\text { Emphasis on } \\
\text { equality and human } \\
\text { rights of all } \\
\text { individuals }\end{array}$ & $\begin{array}{l}\text { Emphasis on equality } \\
\text { and human rights of all } \\
\text { individuals }\end{array}$ & $\begin{array}{l}\text { Emphasis on equality } \\
\text { and human rights of } \\
\text { all individuals }\end{array}$ \\
\hline $\begin{array}{l}\text { Policy concern } \\
\text { with rights and } \\
\text { freedoms }\end{array}$ & $\begin{array}{l}\text { Ultimate end has } \\
\text { intrinsic value; there } \\
\text { is a priority for both } \\
\text { rights and freedoms }\end{array}$ & $\begin{array}{l}\text { Ultimate end has } \\
\text { intrinsic value; there is } \\
\text { a priority for both } \\
\text { rights and freedoms }\end{array}$ & $\begin{array}{l}\text { Ultimate end has } \\
\text { intrinsic value; there is } \\
\text { a priority for both } \\
\text { rights and freedoms }\end{array}$ \\
\hline
\end{tabular}


institutions and citizens as they develop and implement policies based on access and inclusion. Operationalizing the CMD also helps to further point out the differences and benefits of the model vis-à-vis Sen's and Nagata's.

The modified CMD presented herein addresses theoretical gaps to social inclusion and uses the CMD to define successful outcomes and structure disability-related policy approaches. As such, the CMD focuses policy interventions on supporting the ability of the individual within a specific context. This framework also benefited from a grounded theory approach developed through interviews and focus groups. The grounded theory helped identify and define a range of policy interventions across nine specific dimensions. The dimensions were defined through triangulation and pattern matching in coded interviews. These nine policy dimensions offer an integrated and practical lens from which to initiate cross-sectoral reforms. Four of these dimensions (health, rehabilitation, education, and employment) are aimed at increasing basic functionings; whereas the other five dimensions (political and public participation, awareness raising, independent and community living, mobility, and accessibility) are targeted toward increasing basic freedoms. Ultimately, the theory attempts to further equity, social justice, and progress for this marginalized and underserved community.

The Iceberg of Inequality model helps to highlight the primary rights in a hierarchical form. As shown in Fig. 3.2, the basic functionings provide a baseline from which to build and expand capabilities through increasing basic freedoms.

Basic functionings are differentiated from basic freedoms in the following ways:

1. Basic functionings are understood as primary needs and thus fundamental to the enjoyment of all of an individual's rights.

2. Basic freedoms are necessary to expand basic functionings into capabilities, which are in themselves the goal of development. Basic freedoms allow for capabilities and functionings to be converted into social value. They also allow persons with disabilities to live the type of life they "have reason to value" (Sen 1999). Capabilities can also be presented as a function of an individual's basic functionings (BFn) and basic freedoms (BFr):

Capabilities $=f(B F n+B F r)$ 


\section{Pineda Pyramid of Disability Policy}

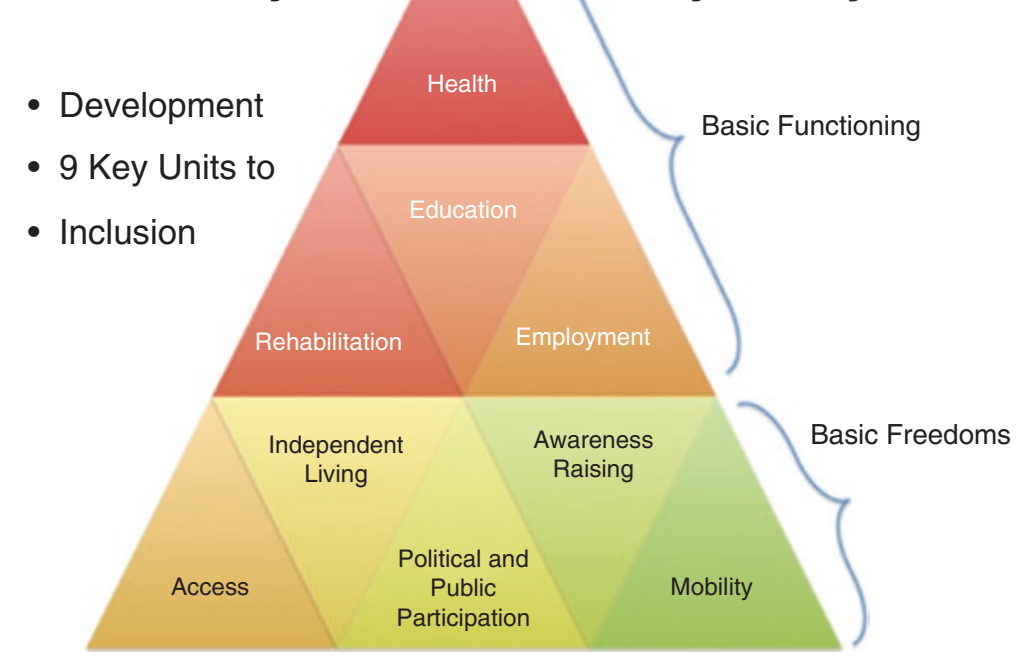

Fig. 3.2 "Iceberg of Inequality" features basic functionings and basic freedoms as organizing domains and as policy areas of interest

\section{Exclusion as Capability Deprivation}

The negative social effects of capability deprivation, as highlighted in the reality lived by persons with disabilities, underscore the enormous cost of not dealing comprehensively with the issue. Sen's research on social exclusion shows that poverty is linked to isolation and marginalization, and oftentimes leads to violence through physical and/or sexual abuse. He also defines poverty as "capability depravity," which is understood as dehumanizing, disabling, and challenging the integrity of already challenged individuals. ${ }^{2}$

\footnotetext{
${ }^{2}$ These perspectives on the importance of dealing with inequality, social exclusion, and poverty of persons with disabilities are mirrored in the differences and views of their origin. By and large, many view disability as arising out of individual tragedy — a tragedy that needs to be addressed through direct support or charity. Alternatively, disability is also seen as a medical abnormality that needs medical and scientific attention to "cure" or eliminate. For adopters of such individualistic viewpoints, social inclusion is only possible under a perfectly "normalized" body and the restoration of full human functioning is seen as the only path toward full citizenship.
} 


\section{CMD Improves Outcomes}

The Capability Model of Disability changes the approach to disability policy and planning in concrete ways. It seeks to remediate past shortcomings and failures not only by providing new approaches to setting and monitoring a baseline, but also by increasing the capacity of domestic actors in implementation. It also provides methods for measuring the domestic salience for international disability norms.

\section{Conclusion}

In my experience observing disability policy across various countries, I noticed that states with good governance and deliberative institutions increased the capability of social institutions and this in turn fostered more capabilities for disabled individuals. ${ }^{3}$ I also discovered that there are persistent negative attitudes and a lack of awareness about the capabilities of persons with disabilities in many countries that derive from a variety of cultural factors, including the unique advantages and disadvantages of individualism versus collectivism in each given society. These negative factors create barriers to changing institutions and contribute to sub-optimal outcomes exacerbated by state policies that do not promote social inclusion for persons with disabilities.

By incorporating domestic salience into a new and culturally specific capability-based model of disability, we can highlight the role that attitudes and beliefs play as either a retardant to social reform or a catalyst to increasing the rate of social and institutional change. Thus, salience must form part of a new and more nuanced assessment of social reforms. The

\footnotetext{
${ }^{3}$ Sen's concepts of agency, capability, and functionings enable him to argue persuasively for democracy's three-fold importance. Ethics of Global Development offers a moral reflection on the ends and means of local, national, and global efforts to overcome these five scourges. After emphasizing the role of ethics in development studies, policymaking, and practice, David A. Crocker analyzes and evaluates Amartya Sen's philosophy of development in relation to alternative ethical outlooks. He argues that Sen's recent turn to robust ideals of human agency and democracy improves on both Sen's earlier emphasis on "capabilities and functionings" and Martha Nussbaum's version of the capability orientation. This agencyfocused capability approach is then extended and strengthened by applying it to the challenges of consumerism and hunger, the development responsibilities of affluent individuals and nations, and the dilemmas of globalization. Throughout the book, the author argues for the importance of more inclusive and deliberative democratic institutions. See Crocker, D. A. (2008). Ethics of global development: agency, capability, and deliberative democracy. Cambridge; New York: Cambridge University Press.
} 
following chapters explore how governance and access have evolved in the city-state of Dubai, and how key events institutionalized policies and programs that would usher in one of the world's most dynamic urban transformations of disability rights.

\section{REFERENCES}

Cheloff, S. P. "Culture, Attitude, and Disability Policy: The Effects of Cultural Values on the Implementation of National Education Policy for Children with Disabilities," 2000.

Cortell, Andrew P., and James Davis Jr. "Understanding the Domestic Impact of International Norms: A Research Agenda." International Studies Review 2, no. 1 (2000): 65-87.

Hanson, M. J., P. Wolfberg, C. Zercher, M. Morgan, S. Gutierrez, D. Barnwell, and P. Beckman. "The Culture of Inclusion: Recognizing Diversity at Multiple Levels." Early Childhood Research Quarterly 13, no. 1 (1998): 185-209.

Hays, P. A. "Addressing the Complexities of Culture and Gender in Counseling." Journal of Counseling and Development 74, no. 4 (1996): 332-38.

Henkin, Louis. How Nations Behave: Law and Foreign Policy. 2 New York: Published for the Council on Foreign Relations by Columbia University Press, 1979.

Hofstede, G. Cultures and Organizations: Software of the Mind. London: McGrawHill, 1991.

Karr, Valerie L. "An International Perspective on Human Rights, SelfDetermination, and Quality of Life of Persons with Disabilities." Columbia University, 2009.

Mitra, Sophie. "The Capability Approach and Disability." Journal of Disability Policy Studies 16, no. 4 (2006): 236-47. https://doi.org/10.1177/1044207 3060160040501 .

_. "The Human Development Model of Disability, Health and Wellbeing." In Disability, Health and Human Development, 9-32. Springer, 2018.

Sen, Amartya Kumar. Development as Freedom. 1st Anchor. New York: Knopf, 1999. http://site.ebrary.com/lib/ucmerced/Doc?id=2002145.

Shakespeare, Tom. "Disability: Suffering, Social Oppression, or Complex Predicament?" edited by Marcus Düwell, Christoph Rehmann-Sutter, and Dietmar Mieth. Springer Netherlands, 2008.

Trani, Jean-Francois, Parul Bakhshi, Nicolò Bellanca, Mario Biggeri, and Francesca Marchetta. "Disabilities Through the Capability Approach Lens: Implications for Public Policies." ALTER - European Journal of Disability Research/Revue Européenne de Recherche Sur Le Handicap 5, no. 3 (July 2011): 143-57. https://doi.org/10.1016/j.alter.2011.04.001.

Turnbull, A. P., and H. R. Turnbull. "Self-Determination for Individuals with Significant Cognitive Disabilities and Their Families." Journal of the Association for Persons with Severe Handicaps 26, no. 1 (2001): 56-62. 
Open Access This chapter is licensed under the terms of the Creative Commons Attribution 4.0 International License (http://creativecommons.org/licenses/ by $/ 4.0 /)$, which permits use, sharing, adaptation, distribution and reproduction in any medium or format, as long as you give appropriate credit to the original author(s) and the source, provide a link to the Creative Commons licence and indicate if changes were made.

The images or other third party material in this chapter are included in the chapter's Creative Commons licence, unless indicated otherwise in a credit line to the material. If material is not included in the chapter's Creative Commons licence and your intended use is not permitted by statutory regulation or exceeds the permitted use, you will need to obtain permission directly from the copyright holder.

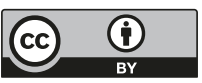

